\title{
Exploring Silence Embedded in Three Selected Sonnets
}

\author{
Nwe Nwe Hlaing \\ Department of English, Yangon University of Education, Yangon, Myanmar
}

Email address:

nwenwehlaing.yuoe@gmail.com

\section{To cite this article:}

Nwe Nwe Hlaing. Exploring Silence Embedded in Three Selected Sonnets. English Language, Literature \& Culture.

Vol. 5, No. 3, 2020, pp. 98-106. doi: 10.11648/j.ellc.20200503.14

Received: August 2, 2020; Accepted: August 18, 2020; Published: August 27, 2020

\begin{abstract}
Most sonnets are love poems, but a vast array of subjects can be embedded in sonnets. Silence can be considered a fascinating subject in both British and American Poetry as it is usually associated with philosophy and can arouse intense emotions in readers. In poetry, silence is subtly portrayed despite its negative impact on the moods of some poets. This study attempts to explore how silence is seen from different perspectives in relation to selected sonnets. Concepts of love, loss, death, solitude and nature are disclosed via the vivid portrayal of silence which is subject to both favourable and unfavourable contexts provided in poetry. The reign of silence has a profound impact on troubled mind, blissful solitude, pleasant moments and changes in attitudes. Through silence, poets reveal their innermost thoughts and feelings in three sonnets. This study aims to raise readers' awareness of blessings and curses of silence, which can make them thought-provoking in analyzing forms of sonnets and figuring out meanings of silence via denotation and connotation. Both qualitative and quantitative methods were deployed in order to find out similarities and differences of three sonnets in terms of denotation and connotation. Based on the results, the most significant proportion of connotation was employed in 'Sonnet-Silence'. Silence is twofold in each sonnet in that it serves as perfect harmony, sheer bliss or intense grief. Denotative meaning is misleading; it often contradicts connotative meaning. It was found that silence has different layers of meaning indeed. All the poets employ silence as a powerful tool in order to convey interesting messages to readers.
\end{abstract}

Keywords: Silence, Sonnet, Love, Death, Nature, Denotation, Connotation

\section{Introduction}

The nature of silence and its impact on human mind are discussed in three sonnets namely, 'Silence', 'Sonnet-Silence' and 'Silent Noon' written by Thomas Hood, Edgar Allan Poe and Dante Gabriel Rossetti respectively. Thomas Hood (1799-1845) was a gifted punster and professional man of letters [1]. He was an English poet famous for comic verse which appeared at times to be almost a reflex action, serving as a defense against painful emotion [2]. However, his great love for silence related to nature is expressed in his poem titled 'Silence.' When he was young, he was destined to move away from the city to live with his relatives in Scotland. In this regard, he was invigorated by the fresh air and country living [3]. During his stay in the countryside of Scotland, he found country life refreshing. He had a close contact with nature related to silence which serves as a shelter from noise pollution common in cities.

Edgar Allan Poe (1809-1849), an American poet and critic
[4], was recognized for his significant contributions to prose as well as poetry in terms of ideology and human spirit. His alien, abstracted nature, his indifference to natural religion and morality, his abhorrence of purpose in art set him apart from his literary contemporaries [5]. He is different from other poets in terms of his nature, principles and views on religion. At different times in his life, his mother, his adoptive mother and his wife died of tuberculosis [4]. Therefore, the horror and cruelty of death are depicted in his literary works. His poetry tends to reveal his obsession with death. He led an eventful life, so he was often overwhelmed with grief associated with the deceased. Thus, his sonnet 'Sonnet-Silence' stresses that the loss of body distressed him in silence.

Dante Gabriel Rossetti (1828-1882) was a poet as well as a painter. For many years, Rossetti had been in love with Jane Morris [6]. In the late 1870s, much of his work was inspired by his feelings for Jane [6]. His major work is an autobiographical sonnet sequence titled The House of Life (1870) which is about the intense love between a man and a woman [6]. He composed "Silent Noon" using the Italian sonnet format [7]. 
This poem is framed in poetic forms of the Romantic period. This sonnet highlights silence associated with unfailing love and portrays wonderful moments associated with silence. The power of silence is beautifully rendered in each sonnet mentioned above. The aim of this study is to explore the nature of silence and its influence on the mind of each poet. There are two objectives for conducting this study: to analyse connotative and denotative meanings which define or redefine silence in three sonnets and to investigate the form of each sonnet and its content for the purpose of uncovering hidden concepts associated with silence.

\section{Sonnet}

Sonnet originated in Italy in the thirteenth century and was spread to England and other countries [8]. Sonnet usually consists of fourteen lines written in iambic pentameter [4], the most common meter for poets [1]. Sonnet has a particular rhyme scheme. There are two major kinds of sonnet: Petrarchan Sonnet and Shakespearean Sonnet [9].

\subsection{Petrarchan Sonnet}

Petrarchan sonnet regarded as Italian sonnet has been passed down to English poets. This type of sonnet consists of two main rhetorical and formal parts namely, octave and sestet [1]. Octave is made up of the first eight lines, but sestet is a group of the last six lines.

The first four lines of the octave emphasize a proposition whereas the remaining lines/the next four lines restate, qualify or show a marked contrast to them [1]. Octave has the rhyme scheme - abbaabba or abababab, but sestet which is composed of final six lines usually begins with volta regarded as a turn or a shift in theme [1]. Tercet consists of three lines. The first three lines in sestet usually indicate resolution; nevertheless, the last three lines of sestet point out conclusion [1]. Sestet often follows the rhyme scheme cdecde or cdccdc [1], but there may be some exceptions regarding this issue. The Petrarchan form was used by Milton, Wordsworth, Christina Rossetti, Dante Gabriel Rossetti, and other sonneteers. Their sonnets reveal a variety of subjects [9]. Some English poets tend to violate the traditional rules of sonnet [1].

\subsection{Shakespearean Sonnet}

English sonnet also known as Shakespearean sonnet was developed in the sixteenth century and influenced by Shakespeare's own innovations [1]. It is usually composed of three quatrains and a concluding couplet: abab cdcd efef gg [8]. Quatrain is a group of four lines; however, couplet is made up of two lines. There is another alternative called Spenserian sonnet developed by Spenser who linked each quatrain to the next using a continuing rhyme: abab bcbc cdcd ee [9]. Traditionally, either a question or a problem is presented in the first half of a sonnet [8]. The second half of the sonnet includes an answer or resolution [8]. The ninth line in the sonnet usually serves as a turning point called volta; nevertheless, Shakespearean sonnets do not follow this pattern exactly [8]. In fact, volta indicates a shift in tone or mood [8]. Apart from volta, coupet which is composed of two lines encompasses the main idea of the sonnet [8].

\subsection{Petrarchan Sonnet Vs Shakespearean Sonnet}

The problem is established, discussed and resolved in sonnets [1]. Many English sonnets have a stronger division between the second quatrain and the third one to suggest a turn. Moreover, the English sonnet rhymes abab cdcd efef gg, permitting a greater number of rhymes than the Italian sonnet, and is better suited to the relative difficulty of rhyming in English as compared to Italian [1]. Most English sonnets differ from Italian sonnets in terms of form and rhyming. English sonnets usually employ three quatrains and a couplet whereas Italian sonnets consist of octave and sestet. More rhymes are embedded in English sonnets which tend to indicate a turn known as volta between the second quatrain and the third one. Form and content are equally important in analyzing either Italian sonnets or English ones.

\section{Denotation and Connotation}

Denotation is different from connotation in that the first one is related to literal meaning whereas the latter one is associated with meanings created by different individuals based on their feelings and cultures.

\subsection{Denotation}

Denotative meaning also called conceptual meaning is considered the central factor in linguistic communication [10]. It is literal meaning described in dictionaries which can provide surface-level meanings. In this sense, denotative meaning is of great importance in defining contexts and describing things or people despite its own limitations in poetry appreciation. However, meaning is more than denotation [11].

\subsection{Connotation}

Connotative meaning is peripheral compared with conceptual meaning (denotative meaning) in that connotations are relatively unstable [10]. Connotation refers to the personal aspect of meaning, the emotional associations that the word arouses [11]. Connotations vary according to culture, historical period, and the experience of the individual. Connotative meaning is indeterminate and openended [10]. Connotative meaning has different shades of meaning depending on different individuals, emotions inside, cultures adopted. Unlike denotative meaning, connotative meaning is open-ended and can vary due to personal preferences.

\section{Methodology}

This research is both qualitative and quantitative. The qualitative descriptive method was utilized for discovering or 
rediscovering silence in chosen sonnets. After collecting the necessary data, they were carefully read and examined via connotation and denotation $[10,11]$ in accordance with the methodology of new criticism [12]. A close reading was adopted for the purpose of resolving ambiguities and tensions. In the next step, figures of speech, images and symbols related to silence were identified and analysed. Then, structural analysis was conducted. This study also involved discovering tone, mood, point of view and setting regarding text situations. In the next step, interrelationships of aforementioned elements were taken into account in order to arrive at an interpretation. The percentage of each meaning conveyed in each sonnet was calculated and compared. Overall, the selected sonnets were analysed by means of form and content which are indispensable.

\section{Portrayal of Silence in Three Sonnets}

For the purpose of exploring silence in selected sonnets, the following research questions were raised in accordance with the aim and objectives of the study.

1. What is sonnet? What are two main types of sonnet?

2. How is silence depicted in three sonnets via denotation and connotation?

3. In what ways is silence portrayed in each sonnet in terms of form and content of the sonnet?

Silence is embedded in three selected sonnets. It is usually associated with beautiful nature, frightening death and enduring love.

\subsection{Silence Associated with Nature}

'Silence' first published in 1950 deserves its popularity [13]. This sonnet was written by Thomas Hood and it provides readers with comparative views on silence in different settings. The rhyme scheme adopted in this sonnet is abba abba cdcd ee [13].

Silence

There is a silence where hath been no sound,

There is a silence where no sound may be,

In the cold grave - under the deep, deep sea,

Or in wide desert where no life is found,

Which hath been mute, and still must sleep profound;

No voice is hush'd - no life treads silently,

But clouds and cloudy shadows wander free,

That never spoke, over the idle ground:

But in green ruins, in the desolate walls

Of antique palaces, where Man hath been,

Though the dun fox or wild hyena calls,

And owls, that flit continually between,

Shriek to the echo, and the low winds moan-

There the true Silence is, self-conscious and alone [14].

Anaphora, which refers to the repetition of a word or expression, is found in the first quatrain. It is described as follows:

'There is a silence where hath been no sound,

There is a silence where no sound may be.'

Silence cannot be spoken or heard; it is unspeakable or inaudible. Silence reveals itself in the absence of sounds. Based on lines 3 and 4 (In the cold grave-under the deep, deep sea/ Or in wide desert where no life is found) in the first quatrain, silence upon the cold grave keeps its secret. Moreover, the poet describes that silence can be under the sea whose depth is unthinkable. In reality, silence is the beauty of the deep sea. It comes alive when no word is uttered or no sound is made. It tends to linger in a vast desert or in a cold grave. If there is no voice, there will be no life. Therefore, silence denotes that no one exists in the empty desert.

In the second quatrain, silence can induce sound sleep which can remove physical weariness. The expressions such as 'mute', 'no voice' and 'never spoke' reinforce the existence of silence. The seventh and eighth lines (But clouds and cloudy shadows wander free/ That never spoke, over the idle ground) in the second quatrain mean that clouds wander aimlessly in silence and silence can be traced above the low ground. The tone of the poet is relaxing as well as carefree. The sea, the wide desert and clouds in the sonnet represent part of nature which is silent. They can bring peace and stillness to the poet and they are cure for tiredness. Thus, silence associated with nature is much appreciated. The first two quatrains involve the subtlety of silence in relation to the physical features of nature, but they exclude the poet's personal or innermost feelings and confused thoughts.

The first quatrain and the second one create an invigorating environment filled with silence which connotes emptiness as well as virtue.

The third quatrain depicts the different silence which can be marked as a shift. In this regard, silence hangs over the ruins of abandoned buildings in remote areas. The use of 'But in green ruins, in the desolate walls' in the ninth line serves as a contrast to silence in the natural setting provided in the previous quatrains. Thus, complete silence in these places is occasionally interrupted by the calls of hyenas, foxes and owls. In fact, the third quatrain highlights the second silence upon the ruined buildings which are far from the poet/readers. In these areas, silence is usually broken by the sounds made by animals.

Regarding the first line of the couplet of this sonnet, silence reigns again after the piercing shriek of owls. Deep silence can spread in the places which are completely desolate and makes solitude blissful. The poet can hear the wind moaning in the first line of the couplet. 'The winds moan' means that the wind can make a low sound while it is blowing. The last two lines imply that silence can be lost and found as it can be interrupted by sounds in surroundings which are not under the poet's control. Therefore, silence is not a possession, but it is a natural gift that he deserves. This is absolute silence contributing to self-consciousness and loneliness. As for alliteration, the repetition of the consonant sound $/ \mathrm{s} /$ is found in the last line of the couplet 'There the true Silence is, self-conscious and alone'. In accordance with connotation, the howling wind and the sounds of animals are also part of nature. Silence is virtue in the form of blissful solitude if one enjoys it. If not, it can lead to unbearable loneliness. This sonnet reveals silence which is the period of 
self-consciousness or solitude.

Overall, two types of silence are discussed in this poem. The first eight lines of the two quatrains describe silence related to natural landscape, but the third quatrain portrays silence upon dilapidated buildings left in abandoned places. The places with intermittent silence are portrayed in the third quatrain via denotation. The sonnet deploys imagery traced in 'desolate walls', 'green ruins,' 'wide desert,' 'antique palaces,' 'clouds' and 'cloudy shadows'. These expressions help readers to create mental pictures and deepen their understanding of silence which tends to linger in these places. Silence is desirable as long as there is no disturbance in terms of sounds made by animals. These sounds can relate the poet to the usual life. Regarding connotation, the sonnet points out that it is necessary to silence the mind in order to hear more. Therefore, the word silence in the sonnet has different layers of meanings.

\subsection{Silence Associated with Death}

'Sonnet-Silence' by Edgar Allan Poe was written in 1839 and first published in 1840 [4]. His sonnet differs from others as it consists of 15 lines and employs a new rhyme scheme. He adopts his own style in order to deconstruct the traditional sonnet format [15]. The structure of the sonnet is abab cddcc efefgg. 'Sonnet-Silence' is composed of a quatrain, a cinquain and a sestet [15].

\section{Sonnet- Silence}

There are some qualities- some incorporate things,

That have a double life, which thus is made

A type of that twin entity which springs

From matter and light, evinced in solid and shade.

There is a two-fold Silence-sea and shore-

Body and soul. One dwells in lonely places,

Newly with grass o'ergrown; some solemn graces,

Some human memories and tearful lore,

Render him terrorless: his name's "No More."

He is the corporate Silence: dread him not!

No power hath he of evil in himself;

But should some urgent fate (untimely lot!)

Bring thee to meet his shadow (nameless elf,

That haunteth the lone regions where hath trod

No foot of man,) commend thyself to God! [16]

In the quatrain, it is highlighted that two things co-exist in some cases. In other words, one is never complete without the other. 'Solid and shade' in the sonnet connotes that a shadow will follow its solid object as they are inseparable. ' $A$ double life' and 'twin entity' einforce the notion of coexistence.

Like 'sea' and 'shore', 'body' and 'soul' in the cinquain consisting of five lines can be viewed as a single entity. Twofold Silence can convey the idea of duality. 'One dwells in lonely places' connotes that the body is buried in a grave, a desolate place. 'Sea and shore' and 'grass o'ergrown' are visual images deployed in the sonnet. These places tend to trigger haunted memories related to the loss of the one he loves. In the desolate place filled with deadly silence, he feels utterly forlorn and helpless as the silence associated with death comes to him. In this regard, he is in a desperate plight. Thus, silence is meaningful as well as eerie. It means seriousness regarding connotation. Regarding 'Render him terrorless,' death associated with silence becomes less frightening. It reduces dreadfulness in him as he seems to realize that this time will pass in the end. 'No More' implies the loss of the body, which is a natural occurrence.

A turn is found in the first line of the sestet in that the expression (dread him not) means that he does not feel frightened any more to confront death. In this case, this connotes that there is a change in his attitude towards dealing with death. Moreover, silence lets him discover the past and allows him to think of an effective way of dealing with strong emotions aroused by death. 'He is the corporate Silence' in the first line of the sestet is a metaphor in that death is compared to silence which results in a pensive mood in him. 'Corporate Silence' implies death; thus, silence is associated with loss or death regarded as a serious matter. Death is inevitable or inescapable, so the poet is in despair. However, the thought of seeing God can dispel his fear for death. This can be traced in 'Bring thee to meet his shadow.' Thus, the poet can be regarded as a man with deep religious devotion. On the other hand, he feels frightened due to complete silence which makes him awkward. The poet attempts to communicate the idea of dreadful death while silence is lingering in the sestet. Thus, he conveys this message via 'nameless elf, That haunteth the lone regions where hath trod and No foot of man'. In this case, silence can stir intense emotions and causes terror in the poet. In relation to silence associated with death, it is uneasy to endure the pain caused by this isolation. Although silence engulfs him, he feels relieved in the end. He is likely to meet God after the death of the body.

The second line of the couplet within the sestet implies that his religious belief in God is strong even though the loss of his body is unthinkable. In relation to connotation, silence seems to be the voice of God which he may hear after losing his body. This calms him down.

The sonnet states its objective at the beginning: There is a two-fold Silence - sea and shore-Body and Soul.' The speaker, the poet, tells the reader not to fear the silence of the body, the 'corporate silence' death [4]. In contrast, the other silence, 'his shadow (nameless elf, / Who haunteth the dim regions where hath trod / No foot of man)' is evil [4]. The harmless silence is called 'No more' - but the evil silence is 'Nameless' [17]. Based on the statements above, harmless silence is regarded as 'No more' in that he is grievously wounded inside in silence. Moreover, ominous silence is worse than the previous one and it is a threat to his life. Silence can lead him to sufferings, but it prepares him for an inescapable occurrence called death.

Overall, it can be noted that he tries to seek refuge in silence. Humans are mortal, but one's belief in God is immortal. In this sense, silence can deepen his understanding of mortality as well as immortality. His gloomy mood is the result of silence. On the other hand, silence can empower him to confront his fear within. Private thoughts can be born in silence. The tone of the poet is melancholic as well as 
serious; thus, silence related to despair is reflected in this sonnet. His devotion for God makes him feel relieved. Death is a separation from his relatives or his lover, so silence associated with death is eerie. Part of the soul is silence which can generate private thoughts. Silent thoughts cannot transform his destiny, but they enable him to adapt to an unexpected circumstance called death. The poet seeks for solutions to his emotional problems in silence; therefore, silence is a remedy for emotional sufferings caused by a state of isolation. Silence can be considered noise within because the poet is speaking to himself in terms of thoughts even if no words are uttered.

\subsection{Silence Associated with Deep Love}

Dante Gabriel Rossetti's well-known sonnet 'Silent Noon' from his cycle The House of Life, which he began writing in the late $1840 \mathrm{~s}$, is a fairly faithful adoption of Petrarchan form and development [1]. Despite Rossetti's denial, it is now generally recognized that his sonnets are deeply personal, inspired in part by love and regret for his wife, Elizabeth Siddal, who died in 1862, and in much greater part, especially after 1868, by his love for Jane Morris [18].

'Silent Noon' composed by Rossetti, the master of the sonnets, breaks a cardinal principle of sonnet construction: he destroys the unity of the quatrain [19]. The rhyme scheme of this sonnet is abba acca ddeffe [19].

\section{Silent Noon}

Your hands lie open in the long fresh grass-

The finger-points look through like rosy blooms:

Your eyes smile peace. The pasture gleams and glooms

'Neath billowing skies that scatter and amass.

All round our nest, far as the eye can pass,

Are golden kingcup-fields with silver edge

Where the cow-parsley skirts the hawthorn-hedge.

'Tis visible silence, still as the hour-glass.

Deep in the sun-searched growths the dragonfly

Hangs like a blue thread loosened from the sky:

So this winged hour is dropped to us from above.

Oh! clasp we to our hearts, for deathless dower,

This close-companioned inarticulate hour

When twofold silence was the song of love [1].

The octave establishes the situation and mood [1]. In the octave, the poet gives a description of a peaceful natural scene which emphasizes peace as well as silence fostered by nature. The two lovers are hid by the tall grass. The silent noon is perfect with his beloved in this welcoming atmosphere, he feels thrilled to see his beloved's hands compared to roses whose beauty is incomparable in silence. Simile is traced in 'The finger-points look through like rosy blooms' in that her fingers represent part of nature. He returns his lover's smiles in ecstasy without saying much. 'Tis visible silence' in the last line of the octave is an oxymoron as silence associated with nature and his beloved appears in his inward eye. On the other hand, silence is invisible and abstract. Another simile is employed in order to describe that silence is as still as the hour-glass.' Silence is visible and transparent like the hourglass. Paradox, a self-contradictory statement [12], arises in the eighth line. In reality, silence is invisible and transitory. On the other hand, this silent moment can stand still just for a while. However, the poet wants this moment last longer. Thus, this emphasizes the contradiction of his desire and transient nature of silent moments. In fact, the sand in the hour glass never stops as the time passes. Smiles in his lover's eyes symbolize peace of silence around them.

Silence is depicted as a picture in the octave in that his beloved's finger points and peaceful smiles are beautifully painted. In this regard, 'pasture,' the hawthorn-hedge' and 'fields with silver edge' enable readers to paint visual images in their minds. Nature has wonderful colours which are appealing to the poet; thus, they are visual representations of silence of nature. Therefore, silence is colorful as well as wonderful. Although silence is invisible, it can co-exist with nature and the poet's lover. The first seven lines imply that the poet is in a relaxed mood [19]. The eighth line 'Tis visible silence, still as the hour-glass' in the octave stands suspended in the middle of the poem [19]. It is an independent sentence in the sonnet in that the silent noon is compared to the stillness of the hour-glass. This line helps readers to visualize the image of the pinched center of the hour-glass, which makes the sonnet emblematic [19].

A dragon-fly in the sestet may be sent from heaven which represents peace in mind. The expression, 'winged hour' in line 11, implies the passing moments the two lovers cherish. They may vanish or be separated by an appalling fate; however, the love between them is eternal and will never be eroded by the changing time. 'Deathless dower' is a gift from God [19]. The gift will be beneficial to those who are married. They can be reunited after death. This gift can serve as absolute unity whether they are alive or dead. Death implies complete silence.

'This close-companioned inarticulate hour' in the first line of the couplet refers to silent moments spent by the two lovers. The twofold silence in the last line of the couplet is the same love song sung in their hearts. The poet associates silence with love. Hence, deep affection is revealed in silence. They understand the love shared between them in deep silence. It implies that love is expressed via her gaze while silence is prevailing. Silence is the love song which can be heard or sung through their hearts, which represents timelessness. On the other hand, silence is a thread which ties them and it can be interrupted when they express their love verbally. The pleasant moment of silence is self-destroying as it has its opening and closing times. For Rossetti the sonnet is inherently paradoxical, like the 'song' produced in 'Silent Noon' by a 'twofold silence' [20].

Overall, the poet marks a division between the octave and the sestet [20]. The octave conveys the message of a silent period which seems to stand still whereas the sestet implies that fleeting moments associated with silence which he has to lose. Silence between the two lovers is transitory. Sooner or later, they both will shatter silence by their words of love in the form of a love song. Like the time which is elusive, peace will not be long-lasting. It will pass as the time goes by. The silent noon is not fixed in that place as it keeps moving. On 
the other hand, silence can remind them of parting or separation. They are tongue-tied until they themselves break silent moments spent together. They are living in the present moment and still do not anticipate what destiny they would face. They enjoy each other's company in silence which will not stretch for a long time. Silence is a means of expressing love inside their hearts. Through this poem, the poet tries to pause these fleeting moments spent well with his beloved. Nature is appealing to them who enjoy silence which lets them discover their deep-rooted love within and deepen their understanding of this strong emotion.

\section{Results and Discussion}

Each sonnet has a particular form which involves the poet's perspectives and feelings in organized ways.
Table 1. The Frequency of the Word Silence Used in Three Sonnets.

\begin{tabular}{ll}
\hline Sonnet & $\begin{array}{l}\text { The frequency of the word silence used in } \\
\text { each sonnet }\end{array}$ \\
\hline Silence & 3 times \\
Sonnet- Silence & twice \\
Silent Noon & twice \\
\hline
\end{tabular}

Based on Table 1, the word silence is used three times in the sonnet 'Silence.' The use of silence is found twice in remaining sonnets: 'Sonnet-Silence' and 'Silent Noon.' The word 'silence' is repeated in all these sonnets for the purpose of expressing the existence of silence which often goes unnoticed by readers. Thus, silence is portrayed in interesting ways in each sonnet which attempts to reveal the nature and uniqueness of silence.

Table 2. Two Types of Meaning Found in 'Silence'.

\begin{tabular}{lll}
\hline Line No. & Line in 'Silence' by Thomas Hood & Denotative Meaning \\
\hline 1. & There is a silence where hath been no sound, & $\checkmark$ \\
2. & There is a silence where no sound may be, & $\checkmark$ \\
3. & In the cold grave - under the deep, deep sea, & $\checkmark$ \\
4. & Or in wide desert where no life is found, & $\checkmark$ \\
5. & Which hath been mute, and still must sleep profound; & \\
6. & No voice is hush'd - no life treads silently, & $\checkmark$ \\
7. & But clouds and cloudy shadows wander free, & $\checkmark$ \\
8. & That never spoke, over the idle ground: & $\checkmark$ \\
9. & But in green ruins, in the desolate walls & $\checkmark$ \\
10. & Of antique palaces, where Man hath been, & $\checkmark$ \\
11. & Though the dun fox or wild hyena calls, & $\checkmark$ \\
12. & And owls, that flit continually between, & $\checkmark$ \\
13. & Shriek to the echo, and the low winds moan- & $\checkmark$ \\
14. & There the true Silence is, self-conscious and alone. & $\checkmark$ \\
Total & & \\
\hline
\end{tabular}

Table 2 shows the frequency of two types of meaning in the sonnet 'Silence'. Denotative meaning is found in lines 1 , $2,3,4,5,7,9,10,11$ and 12 whereas connotative meaning is traced in lines 6, 8, 13 and 14 .

The value of silence is traced in both poems: 'Silence' and 'Silence Noon', which gives an important message. This means that readers deserve to be surrounded by the beauty of nature associated with silence. In the sonnet titled 'Silence,' Thomas Hood points out the importance of a silent period that one needs to enjoy. Silence ensures the bliss of solitude associated with part of nature which has healing effects. As part of nature tends to utter no words, it is worth appreciating its beauty in complete silence. In comparison with other poets, he tries to describe the existence of silence in places which are geographically different from readers. He attempts to cultivate a love of nature in a relaxing environment. A profound silence can be maintained in places far away from readers. However, some places are occupied by animals which tend to shatter silence via their cries. Silence can prevail in the absence of human beings. Silence associated with nature is a must at some times in life in order to get rid of monotonous thoughts and capture the moments of blissful solitude contributing to self-consciousness. Both connotation and denotation are truly applicable in exploring silence. Additionally, the form of the sonnet enables readers to locate different kinds of silence quickly.

Table 3. Two Types of Meaning Found in 'Sonnet-Silence'.

\begin{tabular}{lll}
\hline Line No. & Line in 'Sonnet- Silence' by Edgar Allan Poe & Denotative Meaning \\
\hline 1. & There are some qualities- some incorporate things, & $\checkmark$ \\
2. & That have a double life, which thus is made & \\
3. & A type of that twin entity which springs & $\checkmark$ \\
4. & From matter and light, evinced in solid and shade. & $\checkmark$ \\
5. & There is a two-fold Silence-sea and shore- & $\checkmark$ \\
6. & Body and soul. One dwells in lonely places, & $\checkmark$ \\
7. & Newly with grass o'ergrown; some solemn graces, & $\checkmark$ \\
8. & Some human memories and tearful lore, & $\checkmark$ \\
\hline
\end{tabular}




\begin{tabular}{|c|c|c|c|}
\hline Line No. & Line in 'Sonnet-Silence' by Edgar Allan Poe & Denotative Meaning & Connotative Meaning \\
\hline 9. & Render him terrorless: his name's "No More." & & $\checkmark$ \\
\hline 10. & He is the corporate Silence: dread him not! & & $\checkmark$ \\
\hline 11. & No power hath he of evil in himself; & & $\checkmark$ \\
\hline 12. & But should some urgent fate (untimely lot!) & & $\checkmark$ \\
\hline 13. & Bring thee to meet his shadow (nameless elf, & & $\checkmark$ \\
\hline 14. & That haunteth the lone regions where hath trod & & $\checkmark$ \\
\hline 15. & No foot of man,) commend thyself to God! & & $\checkmark$ \\
\hline Total & & 2 & 13 \\
\hline
\end{tabular}

In relation to Table 3, 'Sonnet-Silence' uses denotation in lines 1 and 8 and connotation in lines $2,3,4,5,6,7,9,10$, $11,12,13,14$ and 15.

'Sonnet-Silence' composed by Poe is different from 'Silence' and 'Silent Noon' in that it beckons readers to discover loss and isolation connected with silence. Based on the poem, silence reminds him of the loss of body, imminent danger. He is lost in his silent thoughts. He realizes that no one can escape from immortality. For the purpose of figuring out deep-level meaning, 'lonely places' in the sonnet should not be taken literally. The loss of the one he loves is irreplaceable, so it is painful for him to lose the one he is so close to. He seems to fear silence associated with loneliness and hopelessness; nevertheless, he can turn this fear into bravery which empowers him to meet God after leaving the world. In this sense, he contemplates death in silence. This lessens the anxiety related to the loss of the body to some extent. Then, he feels encouraged to face the reality. Human spirit cannot be conquered by death associated with dreadful silence. Silence helps Poe generate private thoughts in order to make calculated decisions. It also prepares him to cope with vicissitudes of life. Self-actualization is the result of silence. Unlike other sonnets, most expressions in 'SonnetSilence' carry connotative meaning.

Table 4. Two Types of Meaning Found in 'Silent Noon'.

\begin{tabular}{llll}
\hline Line No. & Line in 'Silent Noon' by D. G. Rossetti & Denotative Meaning & Connotative Meaning \\
\hline 1. & Your hands lie open in the long fresh grass- & $\checkmark$ & $\checkmark$ \\
2. & The finger-points look through like rosy blooms: & & $\checkmark$ \\
3. & Your eyes smile peace. The pasture gleams and glooms & $\checkmark$ & $\checkmark$ \\
4. & 'Neath billowing skies that scatter and amass. & & $\checkmark$ \\
5. & All round our nest, far as the eye can pass, & $\checkmark$ & $\checkmark$ \\
6. & Are golden kingcup-fields with silver edge & $\checkmark$ & $\checkmark$ \\
7. & Where the cow-parsley skirts the hawthorn-hedge. & & $\checkmark$ \\
8. & 'Tis visible silence, still as the hour-glass. & & $\checkmark$ \\
9. & Deep in the sun-searched growths the dragonfly & & 9 \\
10. & Hangs like a blue thread loosened from the sky: & & \\
11. & So this winged hour is dropped to us from above. & & \\
12. & Oh! clasp we to our hearts, for deathless dower, & 5 & \\
13. & This close-companioned inarticulate hour & & \\
14. & When twofold silence was the song of love & & \\
Total & & & \\
\hline
\end{tabular}

Based on Table 4, 'Silent Noon' can be analysed via denotation found in lines $1,4,5,7$ and 9 and connotation embedded in lines $2,3,6,8,10,11,12,13$ and 14 .

The main similarity between 'Silent Noon' and 'Silence' is the inclusion of nature. These two sonnets stress that silence is the spirit of nature. The former depicts the two lovers who do not make attempts to break the silence whereas the latter portrays silence close to nature. In the sonnet 'Silent Noon,' the presence of the poet's beloved can gladden his heart. Silence is much appreciated in maintaining or strengthening a relationship, but it is temporary. Love reveals itself with the help of silence which is vividly portrayed in the background of a particular afternoon. Images such as 'pasture', 'grass' and 'the hawthorn-hedge' describes a natural setting. The moments they are spending together can be considered a miracle because they create stillness brought by silence. Momentary silence is desirable in that particular place because it can create a peaceful atmosphere before it is shattered. Like a coin, silence has two sides. It can be considered from two different angles; thus, silence is either short-lived or long-lasting. This is paradoxical. The nature of silence is misleading for those who attempt to discover its definite meaning. Denotative meaning is a must for giving a description of a physical environment whereas connotative meaning can contribute to poetry appreciation at the deep level. The appropriate length of silence is a requirement for renewable love. It seems that words fail to express their love, but silence uncovers this intense emotion in its own ways. As for connotation, silence is not just silence. It is full of words.

Table 5. Percentage of Each Type of Meaning in Three Sonnets.

\begin{tabular}{lll}
\hline Sonnet & Denotative meaning & Connotative Meaning \\
\hline Silence & $(10) 71 \%$ & (4) $29 \%$ \\
Sonnet-Silence & $(2) 13 \%$ & (13) $87 \%$ \\
Silent Noon & (5) $36 \%$ & (9) $64 \%$ \\
\hline
\end{tabular}

Based on Table 5, denotative meaning and connotative 
meaning were converted to percentage.

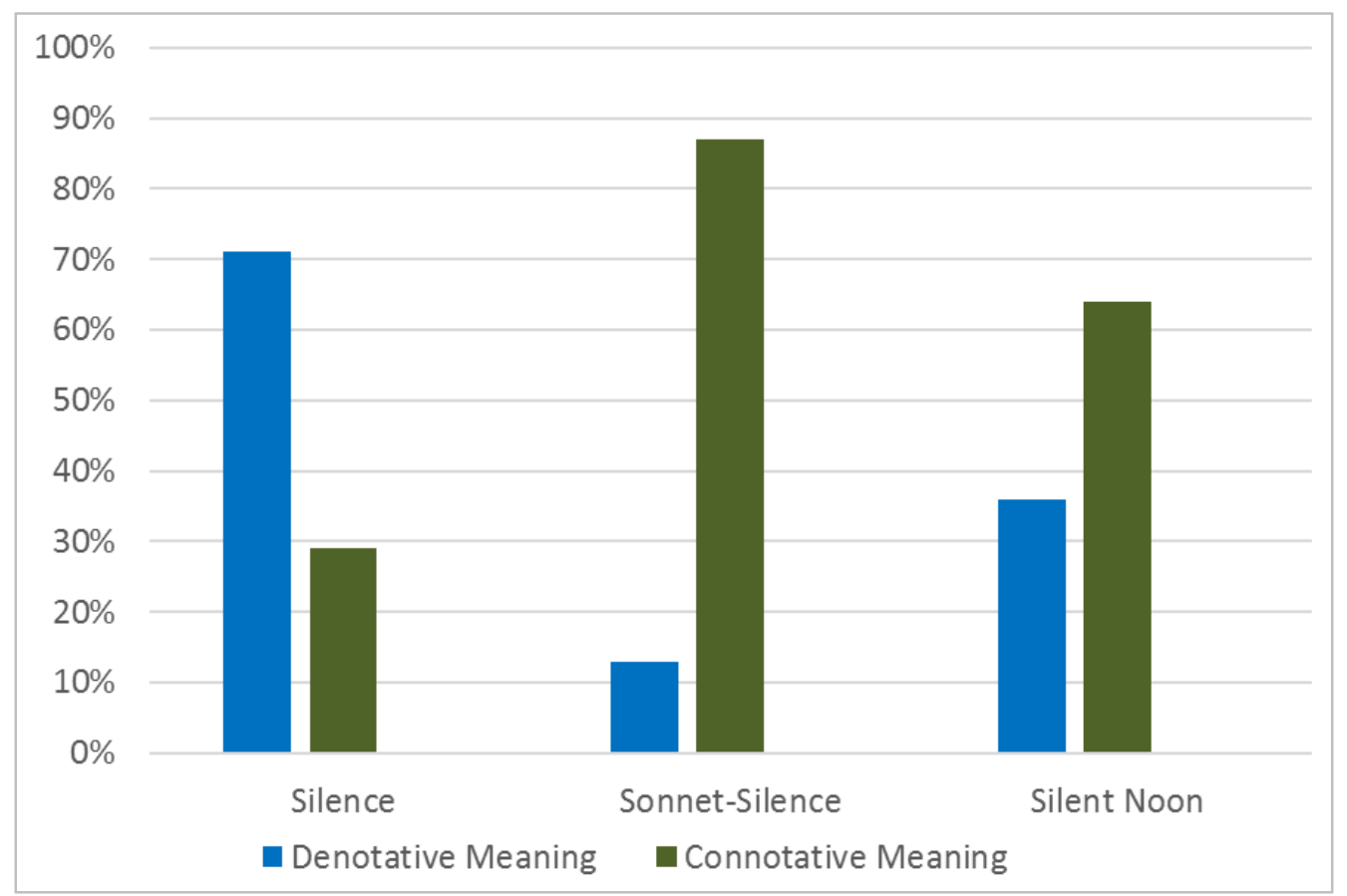

Figure 1. The Comparison of Denotative Meaning and Connotative Meaning Embedded in Three Sonnets.

The comparison of two types of meaning in three sonnets was shown in Figure 1. It can be seen that denotation and connotation conveyed in three selected sonnets vary in proportion.

The highest box represents the use of connotation deployed in 'Sonnet-Silence,' which makes a significant difference. This sonnet has the highest percentage of connotation, $87 \%$. Thus, it is challenging for some readers to figure out meanings in terms of connotation conveyed in 'Sonnet-Silence.' Nevertheless, this sonnet makes up the lowest percentage of denotative meaning, $13 \%$. Therefore, denotative meaning is found the least in 'Sonnet-Silence.'

Compared to other sonnets, the use of connotation in 'Silence' is the least and it has $29 \%$ of connotative meaning. However, the proportion of denotative meaning conveyed in 'Silence' is the highest among the three sonnets. This sonnet comprises the largest percentage, $71 \%$ of denotative meaning. As a result, it is easier for some readers to understand the surface-level meanings of words or expressions in 'Silence' which has the most significant proportion of denotative meaning.

As for Figure 1, denotation ranges from $13 \%$ to $71 \%$ whereas connotation varies from $29 \%$ to $87 \%$. It can be found that $64 \%$ of connotative meaning is conveyed in 'Silent Noon.' This is the second highest. This proportion is significantly higher than that in 'Silence' which has $29 \%$ of connotative meaning.

In contrast to 'Sonnet-Silence' and 'Silent Noon', 'Silence' deals with pure silence closely connected with nature. However, 'Silent Noon' is related to undying love in deep silence of nature. Compared with other sonnets, deadly silence in 'Sonnet-Silence' revitalizes the poet spiritually and makes him express his unshakable faith in God even though that sort of silence can stir intense emotions such as loneliness, distress and terror in the poet.

The couplet in each sonnet tends to convey important messages connected with silence. In relation to sonnets, form and content are inseparable and they are complementary to each other. A shift/volta is usually placed in the first line of the sestet or between the second quatrain and the third quatrain.

The influence of silence on the mind of each poet is undeniable. 'True silence' in the $14^{\text {th }}$ line of 'Silence' is the ultimate silence which comes to the poet when there is no disturbance. In relation to connotation, silence can lead to blissful solitude, peace or privacy.

At the surface level, the expression 'visible silence' in $8^{\text {th }}$ line of 'Silent Noon' means that silence can be visible only for the poet who loves meaningful silence due to his beloved. In terms of connotation, silence is invisible and abstract. It is beyond the poet's control. Invisible silence is related to the changing time that he fears.

'Two-fold Silence' in the $5^{\text {th }}$ line of 'Sonnet-Silence' and 'twofold silence' in the $14^{\text {th }}$ line of Silent Noon' differ in terms of meaning. 'Two-fold Silence' in 'Sonnet- Silence' highlights togetherness or coexistence. This expression connotes that one will perish without the other. 'Twofold silence' in 'Silent Noon' expresses two opposing ideas. This expression means that silence performs two functions. During the period of silence, the two lovers sing the same love song within their hearts. This song can be heard as they understand their deep-rooted love between them. Otherwise, they can break silence and sing that song together. How to 
sing songs is dependent on their choice. This expression also connotes that love is unstoppable, this strong emotion is warm and flows freely within their hearts. Therefore, love is silent inside.

Silence is abstract, but its existence is not in doubt. D. G. Rossetti makes silence concrete via words or expressions in 'Silent Noon'. They help create mental pictures. Thus, the scene painted in the sonnet depicts two lovers and nature during the reign of silence.

The sonnets are pleasing to hear due to the iambic pentameter and rhyming words. The repetition of the word silence in three sonnets define or redefine silence associated with human spirit, death, love and nature. Some words and expressions have both denotative meaning and connotative one. Interpretations may vary depending on individual differences such as cultures, emotions, beliefs, values and experiences.

\section{Conclusion}

Both the form of each sonnet and its content should be taken into consideration as they are indispensable in discovering silence in each of them. In accordance with the findings of the study, each sonnet is unique in defining silence. Silence is unbearable because prolonged silence increases tensions among humans; nevertheless, it would be a great privilege to enjoy silence associated with nature. Silence is mysterious as it can slip out of the place where it has prevailed. In repose, one can enjoy silence if noise leads to suffering or discomfort. When sounds gradually fade away, silence follows. Silence is so powerful that it can deeply distress Poe; therefore, he emphasizes that silence is a matter of life and death. He finds silence dreadful, but it can make him thoughtful. From the point of view of D. G. Rossetti, silence is elusive like the running time. Silence allows the poet to live in a world of fantasy. Deep silence discloses pure love, unspoken words or untold stories. Thomas Hood highlights that a silence period associated with nature is a necessity as it is of great importance for those who take great delight in solitude. Thus, silence leading to a solitary journey has multiple meanings in terms of connotation. Both thematic and structural unity of each sonnet should be taken into account to grasp a deeper understanding of silence. In fact, silence has many surprises to unfold despite its imperfection.

\section{References}

[1] Feldman, P. R. D., Feldman, P. R., \& Robinson, D. (2002). A century of sonnets: The romantic era revival, 1750-1850. New York: Oxford.

[2] https://www.britannica.com/biography/Thomas-Hood

[3] Maunder, A. (2010). Encyclopedia of literary romanticism. New York: Facts On File.

[4] Sova, D. (2007). Critical Companion to Edgar Allan Poe.

[5] Pope-Hennessy, U. (1971). Edgar Allan Poe. Ardent Media.

[6] Krueger, C., L. (2003). Encyclopedia of British Writers, 19th and 20th Centuries, 2-Volume Set.

[7] https://hero033.edublogs.org/poetry-analysis-silent-noon/

[8] Evans, V. J. D. (2020). Pathways to Literature: Student Book (1st ed.). Express Publishing.

[9] Abrams, M. H., \& Harpham, G. G. (2012). A glossary of literary terms. Boston, Mass: Wadsworth.

[10] Leech, G. N. (1981). Semantics: The study of meaning. Harmondsworth, Middlesex, England: Penguin.

[11] Kreidler, C. (2013). Introducing English Semantics (2nd ed.). Routledge.

[12] Bressler, C. E. (2011). Literary criticism: An Introduction to Theory and Practice. Literary Criticism by Charles E. Bressler

[13] https://literarydevices.net/silence/

[14] Hood, T. (1876). The Choice Works of Thomas Hood.

[15] http://www.davidglensmith.com/lonestar/2327/slides/slides13Sonnet-Poe.pdf

[16] Poe, E. A., \& Thompson, G. R. (2009). Great short works of Edgar Allan Poe: Poems, tales, criticism.

[17] Quinn, A. H., \& Rosenheim, S. (1998). Edgar Allan Poe: A critical biography. Baltimore: Johns Hopkins University Press.

[18] https://rpo.library.utoronto.ca/poems/house-life-19-silent-noon

[19] Spector, S. (1976). Rossetti's Self-Destroying "Moment's Monument": "Silent Noon". Victorian Poetry, 14 (1), 54-58. Retrieved July 10, 2020, from www.jstor.org/stable/ 40001858

[20] Cronin, R., \& John Wiley \& Sons. (2016). Reading Victorian poetry. Chichester: Wiley Blackwell. 